\title{
Physiochemical, rheological, microstructural, and antioxidant properties of yogurt using monk fruit extract as a sweetener
}

\author{
Qingfeng Ban, ${ }^{1,2} \odot$ Zonghao Liu, ${ }^{1}$ Chongwei Yu, ${ }^{1}$ Xiaomeng Sun, ${ }^{1} \odot$ Yunqing Jiang, ${ }^{1,2}$ Jianjun Cheng, ${ }^{1 *}$ \\ and Mingruo Guo ${ }^{2,3 *}$ \\ ${ }^{1}$ College of Food Science, Northeast Agricultural University, Harbin 150030, China \\ ${ }^{2}$ Key Laboratory of Dairy Science of Ministry of Education, Northeast Agricultural University, Harbin 150030, China \\ ${ }^{3}$ Department of Nutrition and Food Sciences, College of Agriculture and Life Sciences, University of Vermont, Burlington 05405
}

\begin{abstract}
A yogurt using monk fruit extract (MFE) as a sweetener was developed. The aim of the study was to investigate the viability of using MFE to develop sweetened yogurts without the calories of added sugar. The physiochemical, rheological, microstructural, and antioxidant properties of yogurt were studied. Rheological results showed that MFE affected the yogurt fermentation process and its rheological properties. Yogurt sweetened with MFE had similar microstructural properties to yogurt sweetened with sucrose. Yogurt with MFE showed higher levels of gly-pro-p-nitroanilide and dipeptidyl peptidase IV inhibitory activities, 1,1-diphenyl-2-picrylhydrazyl radical scavenging capacity, $\alpha$-glucosidase inhibitory activities, and superoxide anion radical scavenging ability compared with other yogurt samples. Results indicated that MFE could be a novel sweetener and a food antioxidant for functional yogurt and related products.
\end{abstract}

Key words: monk fruit extract, sweetener, rheological, antioxidant properties

\section{INTRODUCTION}

Yogurt is considered one of the major dairy products (Ramírez-Sucre and Vélez-Ruiz, 2013; Miele et al., 2017a). These products are gaining global recognition as healthy foods due to their nutritional and health benefits (Miele et al., 2017a). Sweeteners such as sucrose are generally added to make yogurts more palatable (Pinheiro et al., 2005; Ramírez-Sucre and Vélez-Ruiz, 2013; Wang et al., 2019).

The risk of obesity and diabetes mellitus will greatly increase if one takes an excessive amount of calories, which has been confirmed as one of the primary causes of these diseases (Howard and Wylie-Rosett, 2002;

Received April 12, 2020

Accepted June 10, 2020.

*Corresponding authors: mguo@uvm.edu and cheng577@163.com
Murphy and Johnson, 2003). To lower the risk requires people to reduce the intake of sugar. In the diet, sugar can be replaced by low- or noncaloric alternative sweeteners. Alternative sweeteners can be classified into 2 types of sweeteners, natural or synthetic, based on their sources, or into intense and bulk sweeteners, based on their sweetness potency (Kinghorn et al., 1998). Synthetic sweeteners such as aspartame, saccharin, sucralose, and acesulfame- $\mathrm{K}$ are extensively applied in food industry (Moure et al., 2006). Given the negative consumer attitudes toward synthetic sweeteners, the food industry has been seeking natural alternative sweeteners (Moure et al., 2006).

Siraitia grosvenorii is a perennial vine of the Cucurbitaceae family, and has been cultivated for more than 200 years (Lu and Zhang, 1984). Monk fruit extract (MFE) consists of a group of triterpenoid glycosides, which are regarded as the main active components of the sweet taste and responsible for the main biological functions of monk fruit. Monk fruit has been shown to have health benefits including antitussive, antiasthmatic, antioxidative, liver-protective, glucose-lowering, immunoregulation, and possibly anticarcinogenic properties (Ban et al., 2020). MFE has been used as a sweetener in China, Japan, and the United States, and it is a suitable and safe low-calorie sweetener for people with type 2 diabetes (Qi et al., 2008; Zhou et al., 2009; Xu et al., 2015; Zhou et al., 2018).

Information about using MFE to replace sucrose in dairy products is currently very limited. The aim of the present study was to investigate the physiochemical, rheological, microstructural, and antioxidant properties of yogurt fortified with MFE.

\section{MATERIALS AND METHODS}

\section{Materials}

Monk fruit extract powder was provided by Kemai Biomedical Co. Ltd. (Changchun, China). Monk fruit extract composition was analyzed using HPLC for 
total phenolics $(3.45 \%)$, total flavonoids $(2.24 \%)$, and total mogrosides (87.5\%; colorimetric method). Milk and sucrose were purchased from a local market (Harbin, China). Freeze-dried direct-to-vat starter culture ABY-8 (Acidophilus Bifidobacterium yogurt culture, Chr. Hansen, Milwaukee, WI) was used, containing Bifidobacterium BB-12, Lactobacillus delbrueckii ssp. bulgaricus, Lactobacillus acidophilus LA-5, and Streptococcus thermophilus. Additionally, 1,1-diphenyl2-picrylhydrazyl (DPPH), gly-pro-p-nitroanilide, and dipeptidyl peptidase IV (DPP-IV) were purchased from Sigma-Aldrich (St. Louis, MO), as were all other chemicals and reagents unless otherwise indicated.

\section{Preparation of Yogurt}

Yogurt samples were prepared according to the method of Wang et al. (2012) with some modifications. Raw milk was heated to $60^{\circ} \mathrm{C}$, and sweeteners (MFE, $1 \mathrm{~g} / \mathrm{L}$; sucrose, 35 or $70 \mathrm{~g} / \mathrm{L}$ ) were added slowly. Next, the mix was heated to $85^{\circ} \mathrm{C}$ for $10 \mathrm{~min}$ and then quickly cooled in ice water. The starter culture, ABY-8 $(0.03 \%, \mathrm{wt} / \mathrm{vol})$ was inoculated. After stirring, the mix was fermented at $41 \pm 1^{\circ} \mathrm{C}$ for $5 \mathrm{~h}$. Then the samples were cooled and stored at $4^{\circ} \mathrm{C}$ for further use. Yogurts were prepared using MFE as the sweetener (MY), using combined MFE and sucrose (MCY), and using sucrose alone (CY). Plain yogurt (PY) was also prepared without sweetener. The amounts of sweetener used were based on the reports of Miele et al. (2017b), Wee et al. (2018), and FAF (2019). The 4 formulations are summarized in Table 1.

\section{Chemical Composition}

The yogurt samples were analyzed for total solids, protein, fat, and ash contents using AOAC procedures (AOAC International, 2002). The concentration of total solids was assayed using a forced-air oven. The concentration of protein was determined via the Kjeldahl method, using a conversion factor of 6.38. The concentration of fat was analyzed using the Soxhlet method. The concentration of ash was determined by dry-ashing, using a muffle furnace. Carbohydrate content was calculated from the difference of total solids minus other solid components, as described by Guzmán-González et al. (1999).

\section{Rheological Characterization of Yogurt}

Yogurt gel formation of $16 \mathrm{~mL}$ of milk mixture was monitored using a Haake Mars 40 Rheometer (Thermo Fisher Scientific, Waltham, MA) with a cup-and-bob geometry consisting of coaxial cylinders (outer diameter $27.2 \mathrm{~mm}$; inner diameter $25.08 \mathrm{~mm}$ ). During fermentation, the mixture was held at $41^{\circ} \mathrm{C}$ for $5 \mathrm{~min}$ and subjected to small deformation oscillation for 5 $\mathrm{h}$ at a $1-\mathrm{Hz}$ frequency, applying $0.5 \%$ strain. After a total fermentation time of $5 \mathrm{~h}$, oscillation measurement was continued during cooling from $41^{\circ} \mathrm{C}$ to $4^{\circ} \mathrm{C}$. Elastic modulus $\left(\mathbf{G}^{\prime}\right)$ was measured every $10 \mathrm{~min}$, and time of gelation $\left(\mathrm{T}_{\text {gel }}\right)$ was arbitrarily defined as the first point at which $\mathrm{G}^{\prime}>1 \mathrm{~Pa}$ (Lucey and Singh, 1997). Three replications of each rheological measurement for each sample were performed. We measured $\mathrm{pH}$ before fermentation, when $\mathrm{G}^{\prime}>1 \mathrm{~Pa}$, and after $5 \mathrm{~h}$, using an HI2211 pH/ORP meter (Hanna Instruments, Woonsocket, RI). Each measurement was conducted in 3 replicates (Miele et al., 2017a).

Viscosity was monitored using a Haake Mars 40 Rheometer (Thermo Fisher Scientific) with a plate geometry sensor (diameter $35.00 \mathrm{~mm}$; gap $1.000 \mathrm{~mm}$ ). Viscosity as a function of shear stress or shear rate was monitored at $25^{\circ} \mathrm{C}$ for yogurt samples. The shear rate ranged from $0.001 \mathrm{~s}^{-1}$ to $1,000 \mathrm{~s}^{-1}$. Samples were subjected to constant shear (shear rate of $100 \mathrm{~s}^{-1}$ ) for the first $15 \mathrm{~s}$ and then kept still for 5 min before viscosity analysis (Fu et al., 2018).

The oscillation test was monitored using the Haake Mars 40 Rheometer (Thermo Scientific) with plate geometry sensor (diameter $35.00 \mathrm{~mm}$; gap $1.000 \mathrm{~mm}$ ). A frequency sweep was conducted $(0.01$ to $100 \mathrm{~Hz})$ at a strain of $1 \%$. Measurements of $\mathrm{G}^{\prime}$ were recorded automatically (Fu et al., 2018).

\section{Determination of Syneresis}

Syneresis was determined according to the method of Hassan et al. (2015) with some modifications. Yogurt samples were centrifuged at $2,000 \times g$ for $25 \mathrm{~min}$ at

Table 1. Formulations of yogurt samples

\begin{tabular}{|c|c|c|c|c|}
\hline Item & Milk (mL) & Sweetener & $\begin{array}{c}\text { Sweetener } \\
\text { level }(\mathrm{g})\end{array}$ & $\begin{array}{c}\text { Starter } \\
\text { culture }(\mathrm{g})\end{array}$ \\
\hline Plain yogurt $(\mathrm{PY})$ & 1,000 & - & - & 0.3 \\
\hline Monk fruit extract yogurt (MY) & 1,000 & Monk fruit extract & 1 & 0.3 \\
\hline Sucrose yogurt $(\mathrm{CY})$ & 1,000 & Sucrose & 70 & 0.3 \\
\hline
\end{tabular}


$4^{\circ} \mathrm{C}$. The supernatant was removed within $5 \mathrm{~min}$, and the precipitate was weighed. The syneresis value was calculated as follows $(\mathrm{W}=$ weight $)$ :

$$
\begin{gathered}
\text { Syneresis value, } \%= \\
\left(\mathrm{W}_{\text {supernatant }} / \mathrm{W}_{\text {total yogurt sample }}\right) \times 100 \%
\end{gathered}
$$

\section{Cryo-Scanning Electron Microscopy}

The microstructure of the yogurt samples was examined using cryo-scanning electron microscopy (XL30 ESEM FEG, Philips Electron Optics, Eindhoven, the Netherlands). All samples were prefrozen using liquid nitrogen. Frozen yogurt samples were transferred into the preparation chamber and fractured using a cold scalpel blade at $-140^{\circ} \mathrm{C}$. Fractured samples were then etched at $-85^{\circ} \mathrm{C}$ for $10 \mathrm{~min}$ and coated with $300 \AA$ of sputter-coated gold. Images of the samples were obtained at $5 \mathrm{kV}$ (Prasanna et al., 2013; Hussain et al., 2017).

\section{Preparation of Yogurt Supernatant}

Yogurt supernatant was prepared according to the method of Abdel-Hamid et al. (2020) with some modification. Yogurt samples were centrifuged $(20,000 \times g$, $30 \mathrm{~min}, 4^{\circ} \mathrm{C}$ ). Supernatant of the yogurt samples was filtered using a $0.45-\mu \mathrm{m}$ syringe filter. The supernatant filtrates were used as the sample stock solution in the measurement of antioxidant properties.

\section{Antioxidant Activity}

The DPPH radical scavenging capacity assay was carried out according to the procedure described by Muniandy et al. (2016), with some modification. The DPP-IV activity was determined by the method of Yan et al. (2020) with slight modifications. The $\alpha$-glucosidase inhibition activity was measured according to to the method of Apostolidis et al. (2006). The superoxide anion radical scavenging ability was evaluated via the method of Li et al. (2012), with some modifications.

\section{Statistical Analysis}

Data are presented as mean \pm standard deviation of 3 samples in each group. Analysis was performed in SPSS 17.0 (SPSS Inc., Chicago, IL). Differences among groups were assessed and analyzed via one-way ANOVA and Duncan's multiple range test. According to the results, a value of $P<0.05$ demonstrated a statistical difference.

\section{RESULTS AND DISCUSSION}

\section{Chemical Composition}

The types of milk used and formulations play a role in the chemical composition of yogurt samples (Wang et al., 2012). The average composition of the yogurt samples containing different sweeteners are given in Table 2. Compared with the PY group, no significant effect of sweeteners $(P>0.05)$ on the protein, fat, ash, and $\mathrm{pH}$ content was detected. Total solids and total carbohydrate contents increased significantly $(P<$ 0.05) upon addition of sucrose in the $\mathrm{CY}$ and $\mathrm{MCY}$ groups, compared with the PY and MY groups (Table 2 ). Monk fruit extract has been reported to contribute 50 to 400 times more sweetness relative to sucrose (Takasaki et al., 2003).

\section{Rheological Properties of Yogurt}

During the process of yogurt fermentation, lactose transforms into lactic acid. As a result, the decrease in $\mathrm{pH}$ enables reduction of the net negative charges of the casein micelle and colloidal calcium phosphate, which serves to bind the casein micelle together (Walstra, 1990; Horne, 1998). By leaching the colloidal calcium

Table 2. Chemical composition and $\mathrm{pH}$ of yogurt samples ${ }^{1}$

\begin{tabular}{lrrrr}
\hline Item & \multicolumn{1}{c}{ PY } & \multicolumn{1}{c}{ MY } & \multicolumn{1}{c}{ MCY } & \multicolumn{1}{c}{ CY } \\
\hline TS (\%) & $13.55 \pm 0.23^{\mathrm{a}}$ & $13.95 \pm 0.59^{\mathrm{a}}$ & $15.67 \pm 0.32^{\mathrm{b}}$ & $19.59 \pm 0.57^{\mathrm{c}}$ \\
Protein (\%) & $3.35 \pm 0.04^{\mathrm{a}}$ & $3.34 \pm 0.05^{\mathrm{a}}$ & $3.34 \pm 0.02^{\mathrm{a}}$ & $3.31 \pm 0.03^{\mathrm{a}}$ \\
Fat (\%) & $3.00 \pm 0.15^{\mathrm{a}}$ & $3.02 \pm 0.12^{\mathrm{a}}$ & $2.99 \pm 0.11^{\mathrm{a}}$ & $2.96 \pm 0.13^{\mathrm{a}}$ \\
Carbohydrates (\%) & $7.2 \pm 0.38^{\mathrm{a}}$ & $7.6 \pm 0.4^{\mathrm{a}}$ & $9.34 \pm 0.25^{\mathrm{b}}$ & $13.32 \pm 0.35^{\mathrm{c}}$ \\
Ash (\%) & $0.58 \pm 0.01^{\mathrm{a}}$ & $0.57 \pm 0.01^{\mathrm{a}}$ & $0.60 \pm 0.01^{\mathrm{a}}$ & $0.61 \pm 0.02^{\mathrm{a}}$ \\
pH & $4.55 \pm 0.15^{\mathrm{a}}$ & $4.37 \pm 0.21^{\mathrm{a}}$ & $4.41 \pm 0.12^{\mathrm{a}}$ & $4.43 \pm 0.10^{\mathrm{a}}$ \\
\hline
\end{tabular}

${ }^{a-c}$ Means within a row with different superscript letters indicate significant differences $(P<0.05)$.

${ }^{1}$ Mean results of 3 independent trials $\pm \mathrm{SD}$. PY = plain yogurt, unsweetened; MY = monk fruit extract yogurt; $\mathrm{MCY}=$ monk fruit extract-sucrose yogurt; $\mathrm{CY}=$ sucrose yogurt. 

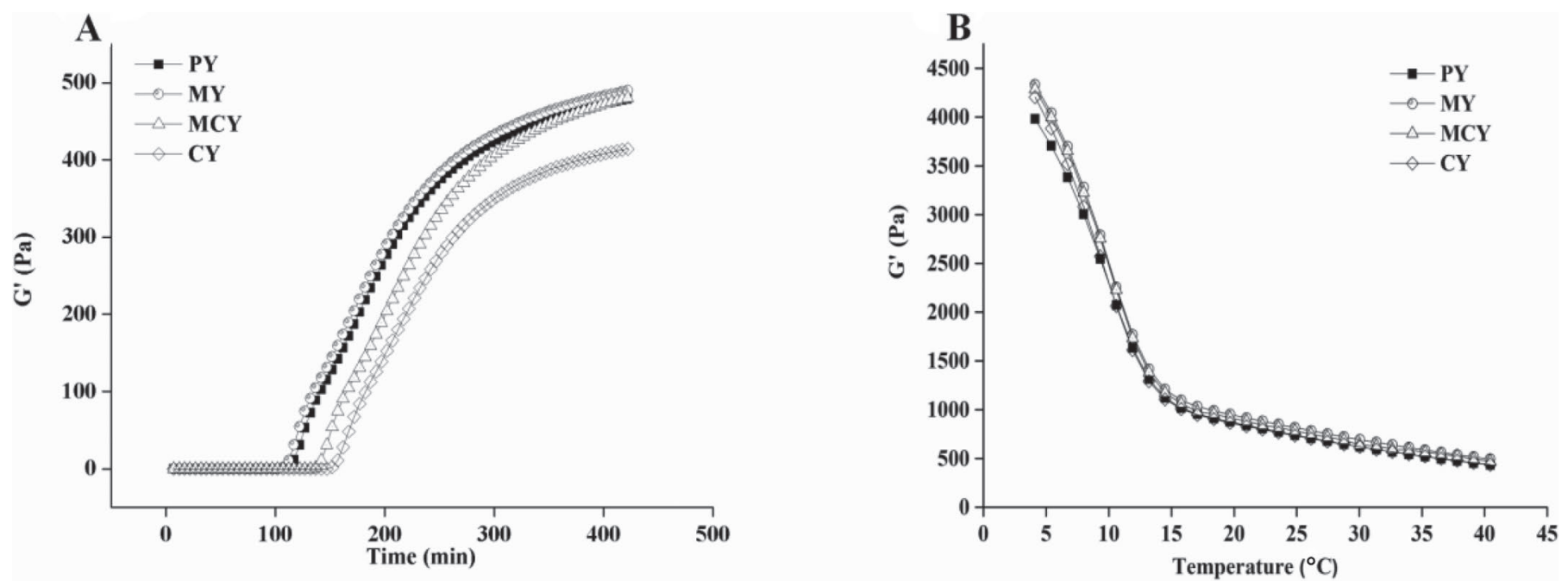

Figure 1. Effects of sweeteners on the rheological characteristics during yogurt fermentation. (A) Elastic modulus $\left(\mathrm{G}^{\prime}\right)$ versus time during milk fermentation at $41^{\circ} \mathrm{C}$ for yogurt samples with or without sweeteners. PY = plain yogurt, unsweetened; $\mathrm{MY}=$ monk fruit extract yogurt; $\mathrm{MCY}=$ monk fruit extract-sucrose yogurt; $\mathrm{CY}=$ sucrose yogurt. (B) $\mathrm{G}^{\prime}$ versus time during cooling from $41^{\circ} \mathrm{C}$ to $4^{\circ} \mathrm{C}$ after fermentation of yogurt samples.

phosphate into serum and maintaining a certain $\mathrm{pH}$ $(\sim 5.2)$, micelle coagulation is initiated. When the $\mathrm{pH}$ reaches the isoelectric point of casein ( $\mathrm{pH} 4.6$ to 4.7), maximum curd firmness will be obtained and the fat globules and residual serum will be entrapped (Afonso and Maia, 1999). The metabolic activity of lactic acid bacteria, which promotes the association of casein micelles by lowering $\mathrm{pH}$, corresponds to an increase in $G^{\prime}$ during fermentation (Bensmira et al., 2010), as observed in yogurt samples during fermentation in the current study (Figure 1). All samples produced the typical gelation kinetic profile of a microbially acidified milk (Haque et al., 2001; Kristo et al., 2011).

After 100 min at $41^{\circ} \mathrm{C}$, the $\mathrm{G}^{\prime}$ value remained low $(\sim 0.1 \mathrm{~Pa})$, characteristic of liquid-like behavior. This was followed by an increase in $\mathrm{G}^{\prime}$ to a value $>1 \mathrm{~Pa}$ between 108 and $152 \mathrm{~min}$, when the highest change in $\mathrm{G}^{\prime}$ was observed, indicating the formation of a 3-dimensional gel structure. For the PY group, this turning point of $\mathrm{G}^{\prime}$ was observed at 115 min, followed by MY $(\mathrm{t}=108 \mathrm{~min}), \mathrm{MCY}(\mathrm{t}=137 \mathrm{~min})$, and $\mathrm{CY}$ group $(\mathrm{t}=152 \mathrm{~min})$, all occurring at approximately $\mathrm{pH} 5.2$ (Figure 1A). After gelation, $\mathrm{G}^{\prime}$ continued to increase but started to plateau from approximately $\mathrm{t}=300 \mathrm{~min}$. Upon cooling, $\mathrm{G}^{\prime}$ increased, first linearly at about 18 $\mathrm{Pa} /{ }^{\circ} \mathrm{C}$, and then exponentially at a maximum rate of about $476 \mathrm{~Pa} /{ }^{\circ} \mathrm{C}$ (Figure 1B).

Table 3 illustrates how the addition of sweeteners resulted in a significant difference in the rheological properties of the yogurt during fermentation at $41^{\circ} \mathrm{C}$ $(P<0.05)$. The MY group registered the highest $\mathrm{G}^{\prime}$ throughout the fermentation and cooling steps. The addition of sweeteners did not significantly affect the rheological properties of the yogurt during cooling to $4^{\circ} \mathrm{C}(P>0.05)$. The final $\mathrm{pH}$ values of the MY, MCY, and $\mathrm{CY}$ groups were similar to that of PY group $(P>$ 0.05). The MY group showed an accelerated effect on the start time of gel formation during fermenting time compared with the other groups. This indicates that MFE may affect the metabolism of starters.

As shown in Figure 2A, when the yogurt body started to flow, the apparent viscosity suggested the influence of shear stress. Hence, the inflection points in the curves clearly suggest an apparent yield stress (Jaros et al., 2007). Slight changes in shear stress in the initial phase resulted in a sharp decline in yogurt viscosity. Similarly, such a tendency was also revealed in the final stage, when high stress was applied, which demonstrated the breakage of the yogurt structure. Even though the yogurt sample was allowed to sit for $5 \mathrm{~min}$ before the viscosity test, a large decrease in shear stress was observed after shear. The results suggest that shear can negatively affect yogurt structure. Yogurt fortified with MFE or sucrose showed decreased apparent yield stress in all batches. Yogurt sweetened with MFE exhibited higher resistance to applied stress, which may be related to a stronger network. According to Jaros et al. (2007), higher values of apparent yield stress have been related to higher degrees of cross-linking of milk proteins in acidified milk.

Figure $2 \mathrm{~B}$ demonstrates $\mathrm{G}^{\prime}$ of yogurt with or without added sweeteners in a frequency sweep $(0.1$ to $100 \mathrm{~Hz})$. 

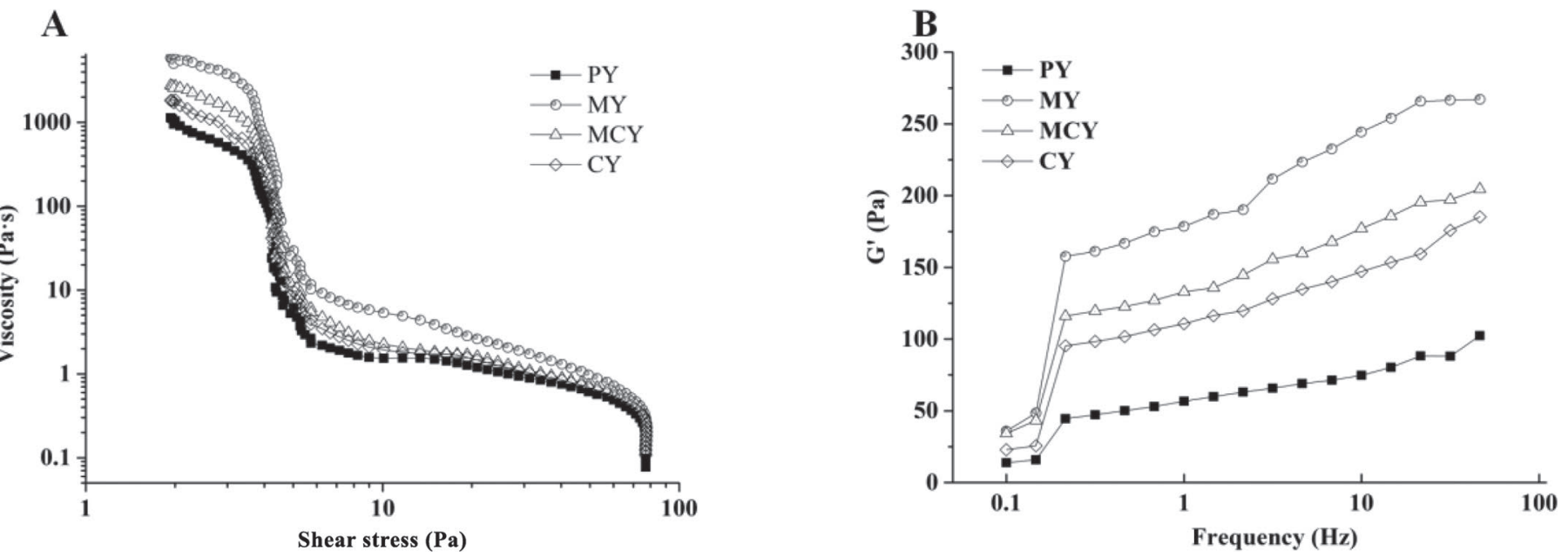

Figure 2. Effects of sweeteners on rheological properties of the yogurt samples. Viscosity profiles (A) and frequency sweep (B) of yogurt samples sweetened with monk fruit extract (MFE) or sucrose. Experiments were performed at $5^{\circ} \mathrm{C}$. PY $=$ yogurt without added sweeteners; $\mathrm{MY}=$ yogurt containing $0.1 \%$ (wt/vol) MFE; MCY = yogurt containing $0.1 \% \mathrm{MFE}$ and 3.5\% (wt/vol) sucrose; CY = yogurt containing $7 \%$ (wt/vol) sucrose. After shear, yogurt samples were pretreated at $100 \mathrm{~s}^{-1}$ for $15 \mathrm{~s}$ and then kept still for 5 min, followed by viscosity analysis.

The PY, MCY, and CY groups showed lower values for $\mathrm{G}^{\prime}$ than did the MY group. Yogurt with $0.1 \% \mathrm{MFE}$ added displayed the highest $\mathrm{G}^{\prime}$ values (35.91 to 267 $\mathrm{Pa}$ ), followed by MCY (34.31 to $204 \mathrm{~Pa}$ ) and CY (22.89 to $185.2 \mathrm{~Pa}$ ), whereas the lowest values were obtained for PY (13.83 to 102.3 Pa). The values for $\mathrm{G}^{\prime}$ for yogurt samples sweetened with $0.1 \%$ MFE were higher than those with added sucrose, which suggests that MFE samples have a stronger gel structure.

In this study, the weaker milk gel of sucrose-sweetened yogurt with a reduced $\mathrm{G}^{\prime}$ value may be due to reduced protein aggregation (Lazaridou et al., 2008, 2014), which depends heavily on the concentration and molecular and structural features of the added substance (Ramirez-Santiago et al., 2010; Corredig et al., 2011). Addition of MFE appeared to affect the gelation and cooling kinetics of the yogurt. When neutral or charged macromolecules were added to the yogurt, certain structural modifications could also be affected (Cui et al., 2014; Pachekrepapol et al., 2015; Fu et al., 2018). Monk fruit extract may interact with amino groups of amino acid residues on the casein micelles. This kind of interaction could increase the net negative micellar charge and increase the hydrophilicity of the micelle surface by incorporation of glycosidic residues, with a corresponding stabilizing effect of both modifications on casein micelle coagulation.

\section{Degree of Syneresis}

A higher degree of syneresis is generally associated with a weak gel, characterized by the presence of larger pore size and a propensity toward casein particle rearrangement in the network of gelled coagulum (Lee and Lucey, 2004, 2006). The addition of sweeteners results in reduction of syneresis in yogurt. Figure 3 indicates a

Table 3. Effects of sweeteners on the rheological parameters during yogurt fermentation ${ }^{1}$

\begin{tabular}{lcccc}
\hline Characteristics $^{2}$ & PY & MY & MCY & CY \\
\hline $\mathrm{T}_{\text {gel }}(\mathrm{min})$ & $115.46 \pm 2.44^{\mathrm{b}}$ & $108.42 \pm 2.38^{\mathrm{a}}$ & $137.02 \pm 1.38^{\mathrm{c}}$ & $152.04 \pm 1.1^{\mathrm{d}}$ \\
$\mathrm{G}^{\prime}{ }_{\text {gel }}(\mathrm{Pa})$ & $4.75 \pm 1.5^{\mathrm{a}}$ & $4.67 \pm 2.27^{\mathrm{a}}$ & $4.52 \pm 1.27^{\mathrm{a}}$ & $5.55 \pm 3.15^{\mathrm{a}}$ \\
$\mathrm{pH}_{\text {gel }}$ & $5.21 \pm 0.00^{\mathrm{a}}$ & $5.25 \pm 0.00^{\mathrm{a}}$ & $5.23 \pm 0.01^{\mathrm{a}}$ & $5.25 \pm 0.08^{\mathrm{a}}$ \\
$\mathrm{G}^{\prime}{ }_{\text {end }}(\mathrm{Pa})$ & $478.85 \pm 16.00^{\mathrm{a}}$ & $489.74 \pm 8.77^{\mathrm{a}}$ & $480.38 \pm 14.35^{\mathrm{a}}$ & $414.21 \pm 12.53^{\mathrm{b}}$ \\
$\mathrm{pH}^{\prime \text { end }}$ & $4.52 \pm 0.02^{\mathrm{a}}$ & $4.50 \pm 0.02^{\mathrm{a}}$ & $4.46 \pm 0.02^{\mathrm{a}}$ & $4.48 \pm 0.04^{\mathrm{a}}$ \\
$\mathrm{G}^{\prime}{ }^{\circ} \mathrm{C}(\mathrm{Pa})$ & $3,981.28 \pm 114.65^{\mathrm{a}}$ & $4,331.86 \pm 199.57^{\mathrm{b}}$ & $4,286.86 \pm 199.57^{\mathrm{b}}$ & $4,205.52 \pm 150.16^{\mathrm{ab}}$ \\
\hline
\end{tabular}

\footnotetext{
${ }^{\mathrm{a}-\mathrm{d}}$ Means within a row with different superscript letters indicate significant differences $(P<0.05)$.

${ }^{1}$ Mean results of 3 independent trials $\pm \mathrm{SD}$. PY = plain yogurt, unsweetened; MY = monk fruit extract yogurt; $\mathrm{MCY}=$ monk fruit extract-sucrose yogurt; $\mathrm{CY}=$ sucrose yogurt.

${ }^{2} \mathrm{~T}_{\text {gel }}=$ time $(\min )$ at which elastic modulus $\left(\mathrm{G}^{\prime}\right)>1 \mathrm{~Pa} ; \mathrm{G}_{\text {gel }}^{\prime}=\mathrm{G}^{\prime}$ at $\mathrm{T}_{\text {gel }} ; \mathrm{pH}_{\text {gel }}=\mathrm{pH}$ at which $\mathrm{G}^{\prime}>1 \mathrm{~Pa}$; $\mathrm{pH}_{\text {end }}=\mathrm{pH}$ after $5 \mathrm{~h}$ of fermentation at $41^{\circ} \mathrm{C} ; \mathrm{G}^{\prime}{ }_{\text {end }}=\mathrm{G}^{\prime}$ after $5 \mathrm{~h}$ of fermentation at $41^{\circ} \mathrm{C} ; \mathrm{G}^{\prime}{ }_{4}{ }^{\circ} \mathrm{C}=\mathrm{G}^{\prime}$ after cooling from $41^{\circ} \mathrm{C}$ to $4^{\circ} \mathrm{C}$.
} 


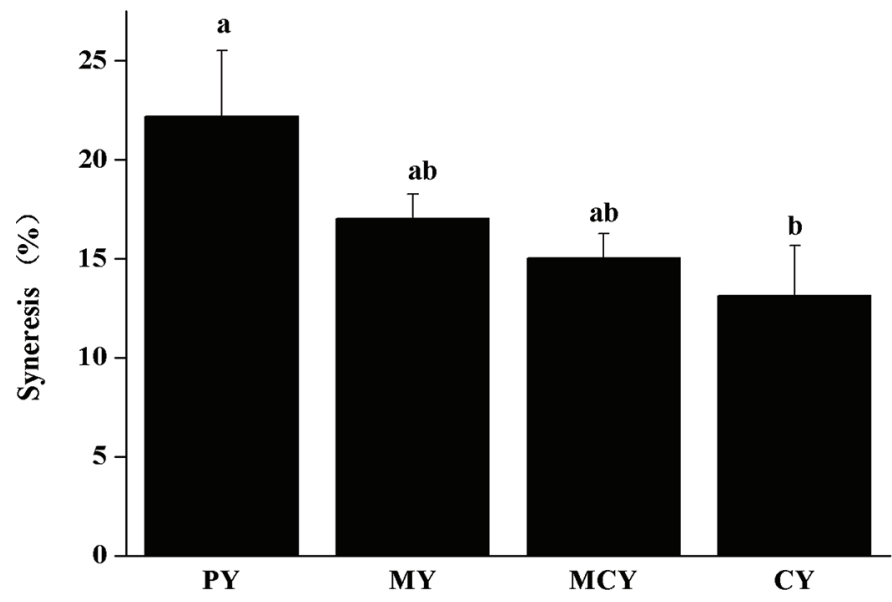

Figure 3. Effects of sweeteners on syneresis of the yogurt samples sweetened with monk fruit extract (MFE) or sucrose. Experiments were performed at $5^{\circ} \mathrm{C}$. PY $=$ yogurt without added sweeteners; MY $=$ yogurt containing $0.1 \%$ (wt/vol) $\mathrm{MFE} ; \mathrm{MCY}=$ yogurt containing $0.1 \% \mathrm{MFE}$ and $3.5 \%$ (wt/vol) sucrose; $\mathrm{CY}=$ yogurt containing $7 \%$ (wt/vol) sucrose. After shear, yogurt samples were pretreated at 100 $\mathrm{s}^{-1}$ for $15 \mathrm{~s}$ and then kept still for $5 \mathrm{~min}$, followed by viscosity analysis. ${ }^{\mathrm{a}, \mathrm{b}}$ Different lowercase letters indicate significant differences $(P<0.05)$. Mean results of 3 independent trials \pm SD.

significant reduction in syneresis of yogurt after adding sucrose $(P<0.05)$, which can be seen as a result of increased total solids. This result might help to explain some phenomena in practice, as sucrose in yogurt products promotes gel formation. However, the addition of MFE did not significantly affect the degree of syneresis for the yogurt samples, compared with the PY and CY groups $(P>0.05)$.

\section{Microstructural Properties}

Figure 4 shows the microstructural properties of PY and yogurts sweetened with sucrose or MFE. Whey protein aggregates, open cavities, and casein micelles were present in all the yogurt samples. Compared with the PY group, yogurt sweetened with sucrose or MFE showed a higher degree of interconnectivity and a denser network. Results suggest that yogurt sweetened with MFE has a similar microstructure to that of yogurt sweetened with sucrose. From previous research, it is reasonable to conclude that the polysaccharide-protein interaction can stabilize the emulsion system and yogurt gels (Dickinson, 2009). Electrostatic interaction can be regarded as predominant if negatively charged polysaccharides were used (Pachekrepapol et al., 2015). Monk fruit extract may interact with amino groups of amino acid residues on casein molecules. Monk fruit extract exhibits the mogrolaglycone structure, with 2 to 5 glucose units attached ( $\mathrm{Li}$ et al. 2014). Mogrosides may interact with the positively charged regions of casein molecules via electrostatic force.

\section{Antioxidant Properties of Yogurt}

The antioxidant properties of yogurt sweetened with MFE or sucrose were determined using the DPP-IV

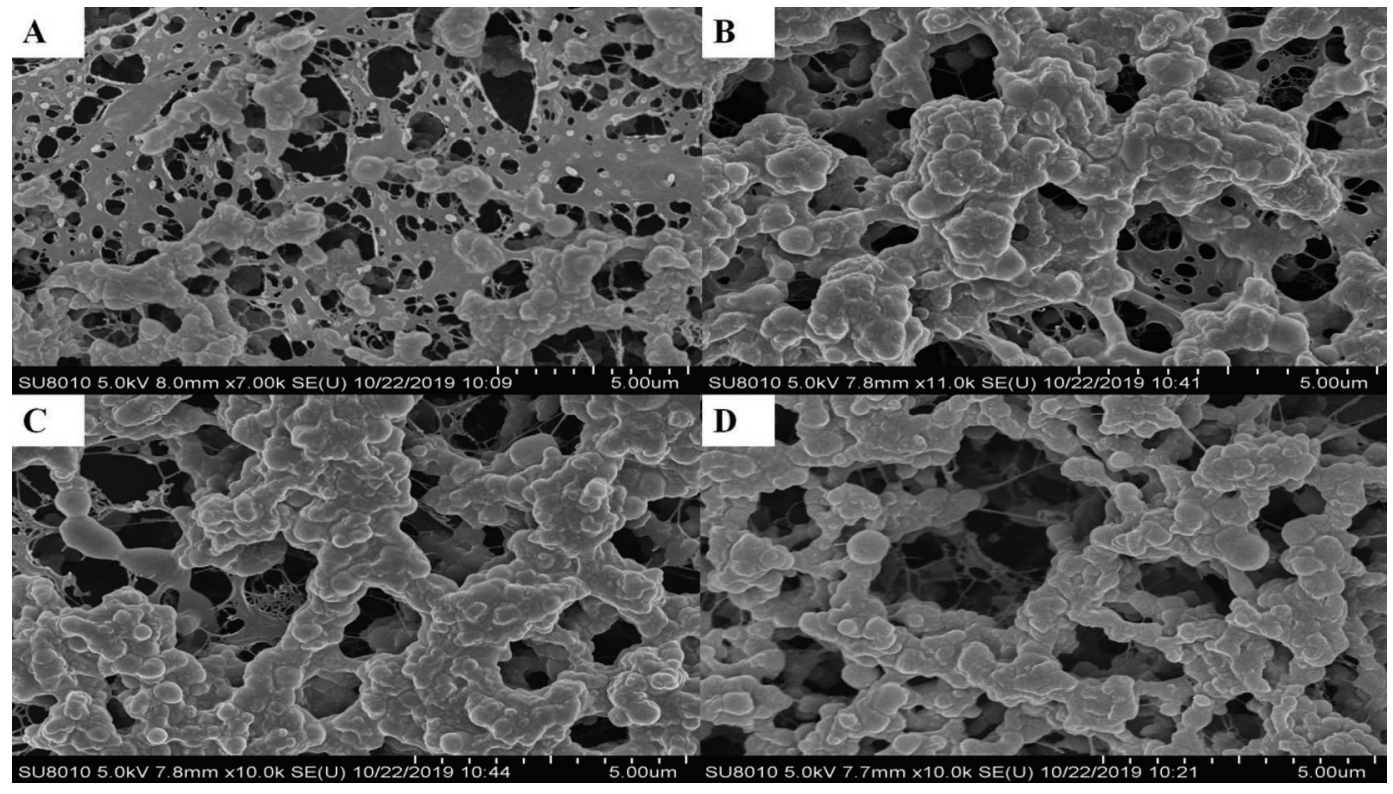

Figure 4. Cryo-scanning electron micrographs of yogurt samples. (A) Yogurt without sweeteners; (B) yogurt sweetened with 0.1\% monk fruit extract; (C) yogurt sweetened with $0.1 \%$ monk fruit extract and $3.5 \%$ sucrose; and (D) yogurt sweetened with $7 \%$ sucrose. Scale bar: $5 \mu$ m. 

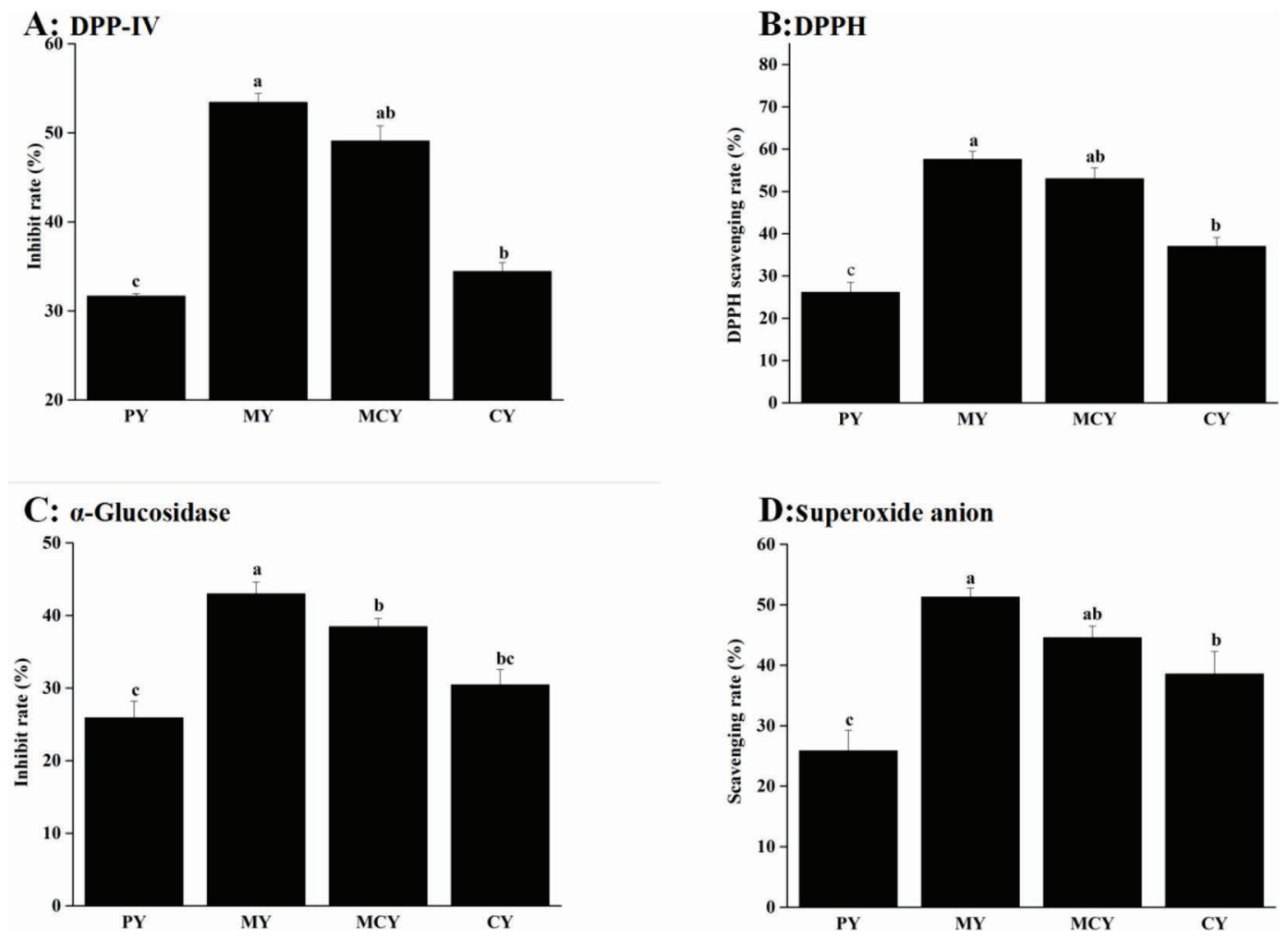

Figure 5. Antioxidant properties of yogurt samples: PY = yogurt without added sweeteners; MY = yogurt sweetened with $0.1 \%$ monk fruit extract; $\mathrm{MCY}=$ yogurt sweetened with $0.1 \%$ monk fruit extract and $3.5 \%$ sucrose; and $\mathrm{CY}=$ yogurt sweetened with $7 \%$ sucrose. Effects on (A) dipeptidyl peptidase IV (DPP-IV) inhibitory activity; (B) 1,1-diphenyl-2-picrylhydrazyl (DPPH) radical scavenging capacity; (C) $\alpha$-glucosidase inhibitory activity; and (D) superoxide anion radical scavenging ability. ${ }^{\text {acc }}$ Different lowercase letters indicate significant differences $(P<0.05)$. Mean results of 3 independent trials \pm SD.

inhibitory activity, DPPH radical scavenging capacity, $\alpha$-glucosidase inhibitory activity, and superoxide anion radical scavenging ability (Figure 5A-D). As shown in Figure 5, the PY group showed lower DPP-IV inhibitory activity, DPPH radical scavenging capacity, $\alpha$-glucosidase inhibitory activity, and superoxide anion radical scavenging ability compared with other yogurt samples. The MY, MCY, and CY groups had higher antioxidant properties compared with the PY group $(P<0.05)$. For the MY, MCY, and CY groups, respectively, DPP-IV inhibitory activity was increased by $68.72 \%, 55.02 \%$, and $8.72 \%$; DPPH radical scavenging capacity was increased by $120.36 \%, 102.9 \%$, and $41.65 \%$; $\alpha$-glucosidase inhibitory activity was increased by $65.9 \%, 48.41 \%$, and $17.53 \%$; and superoxide anion radical scavenging ability was increased by $98.37 \%, 72.4 \%$, and $49.19 \%$. Demirci et al. (2017), and Zhang et al. (2019) reported a significant increase in the antioxidant properties of yogurt produced with fruit extract powder. Based on this research, the increases in the antioxidant properties of yogurt fortified with MFE can be attributed to polyphenols and mogrosides in MFE.

\section{CONCLUSIONS}

Results indicated that MFE is suitable to use as a sweetener for yogurt production. Monk fruit extract may improve rheological properties of yogurt. The addition of $0.1 \%$ or less of MFE was sufficient to substitute for sucrose as a sweetener for yogurt formulation. Use of MFE may also improve the nutraceutical property of yogurt by increasing its antioxidant capacity. The proper selection and use of MFE as a functional ingredient in yogurt appear to be important, as it provides a choice of food for consumers and exhibits health benefits. Data showed that MFE can be used for formulation of yogurt products with low glycemic index that may be suitable for use by diabetic consumers.

\section{ACKNOWLEDGMENTS}

Financial support for this project was provided by a special grant from Northeast Agricultural University (Harbin, China). This project was also supported by the China Scholarship Council (Beijing). The authors have not stated any conflicts of interest. 


\section{REFERENCES}

Abdel-Hamid, M., E. Romeih, Z. Huang, T. Enomoto, L. Huang, and L. Li. 2020. Bioactive properties of probiotic set-yogurt supplemented with Siraitia grosvenorii fruit extract. Food Chem. 303:125400. https://doi.org/10.1016/j.foodchem.2019.125400.

Afonso, I. M., and J. M. Maia. 1999. Rheological monitoring of structure evolution and development in stirred yoghurt. J. Food Eng. 42:183-190. https://doi.org/10.1016/S0260-8774(99)00118-1.

AOAC International. 2002. Official Methods of Analysis, Vol. II. 17th ed. Association of Official Analytical Chemists, Gaithersburg, MD.

Apostolidis, E., Y. I. Kwon, K. Shetty, E. Apostolidis, and Y. I. Kwon. 2006. Potential of cranberry-based herbal synergies for diabetes and hypertension management. Asia Pac. J. Clin. Nutr. 15:433441.

Ban, Q. F., J. J. Cheng, X. M. Sun, Y. Q. Jiang, S. B. Zhao, X. Song, and M. R. Guo. 2020. Effects of a synbiotic yogurt using monk fruit extract as sweetener on glucose regulation and gut microbiota in rats with type 2 diabetes mellitus. J. Dairy Sci. 103:2956-2968. https://doi.org/10.3168/jds.2019-17700.

Bensmira, M., C. Nsabimana, and B. Jiang. 2010. Effects of fermentation conditions and homogenization pressure on the rheological properties of Kefir. Lebensm. Wiss. Technol. 43:1180-1184. https: //doi.org/10.1016/j.lwt.2010.04.005.

Corredig, M., N. Sharafbafi, and E. Kristo. 2011. Polysaccharide-protein interactions in dairy matrices, control and design of structures. Food Hydrocoll. 25:1833-1841. https://doi.org/10.1016/j foodhyd.2011.05.014

Cui, B., Y. Lu, C. Tan, G. Wang, and G. Li. 2014. Effect of crosslinked acetylated starch content on the structure and stability of set yoghurt. Food Hydrocoll. 35:576-582. https://doi.org/10.1016/ j.foodhyd.2013.07.018.

Demirci, T., K. Aktaș, D. Sözeri, H. İ. Öztürk, and N. Akın. 2017. Rice bran improve probiotic viability in yoghurt and provide added antioxidative benefits. J. Funct. Foods 36:396-403. https://doi.org/ 10.1016/j.jff.2017.07.019

Dickinson, E. 2009. Hydrocolloids as emulsifiers and emulsion stabilizers. Food Hydrocoll. 23:1473-1482. https://doi.org/10.1016/j foodhyd.2008.08.005.

EFSA Panel on Food Additives and Flavourings (FAF), M. Younes, G. Aquilina, K.-H. Engel, P. Fowler, M. J. Frutos Fernandez, P. Furst, R. Gürtler, U. Gundert-Remy, T. Husøy, W. Mennes, P. Moldeus, A. Oskarsson, R. Shah, I. Waalkens-Berendsen, D. Wölfle, G. Degen, L. Herman, D. Gott, J.-C. Leblanc, A. Giarola, A. M. Rincon, A. Tard, and L. Castle. 2019. Safety of use of monk fruit extract as a food additive in different food categories. EFSA J. 17:e05921.

Fu, R., J. Li, T. Zhang, T. Zhu, R. Cheng, S. Wang, and J. Zhang. 2018. Salecan stabilizes the microstructure and improves the rheological performance of yogurt. Food Hydrocoll. 81:474-480. https: //doi.org/10.1016/j.foodhyd.2018.03.034.

Guzmán-González, M., F. Morais, M. Ramos, and L. Amigo. 1999. Influence of skimmed milk concentrate replacement by dry dairy products in a low fat set-type yoghurt model system. I: Use of whey protein concentrates, milk protein concentrates and skimmed milk powder. J. Sci. Food Agric. 79:1117-1122. https://doi.org/10.1002/ (SICI) 1097-0010(199906)79:8<1117::AID-JSFA335>3.0.CO;2-F.

Haque, A., R. K. Richardson, and E. R. Morris. 2001. Effect of fermentation temperature on the rheology of set and stirred yogurt. Food Hydrocoll. 15:593-602. https://doi.org/10.1016/S0268 $-005 \mathrm{X}(01) 00090-\mathrm{X}$.

Hassan, L. K., H. F. Haggag, M. H. ElKalyoubi, M. Abd El-Aziz, M. M. El-Sayed, and A. F. Sayed. 2015. Physico-chemical properties of yoghurt containing cress seed mucilage or guar gum. Ann. Agric. Sci. 60:21-28. https://doi.org/10.1016/j.aoas.2014.11.021.

Horne, D. S. 1998. Casein interactions: Casting light on the black boxes, the structure in dairy products. Int. Dairy J. 8:171-177. https://doi.org/10.1016/S0958-6946(98)00040-5.

Howard, B. V., and J. Wylie-Rosett. 2002. Sugar and cardiovascular disease: A statement for health care professionals from the Committee on Nutrition of the Council on Nutrition, Physical Activity, and Metabolism of the American Heart Association. Circulation
106:523-527. https://doi.org/10.1161/01.CIR.0000019552.77778 04.

Hussain, M., S. Bakalis, O. Gouseti, S. Akhtar, A. Hameed, and A. Ismail. 2017. Microstructural and dynamic oscillatory aspects of yogurt as influenced by hydrolysed guar gum. Int. J. Food Sci. Technol. 52:2210-2216. https://doi.org/10.1111/ijfs.13500.

Jaros, D., C. Heidig, and H. Rohm. 2007. Enzymatic modification through microbial transglutaminase enhances the viscosity of stirred yoghurt. J. Texture Stud. 38:179-198. https://doi.org/10 $.1111 /$ j.1745-4603.2007.00093.x

Kinghorn, A. D., N. Kaneda, N. I. Baek, E. J. Kennelly, and D. D. Soejarto. 1998. Noncariogenic intense natural sweeteners. Med. Res. Rev. 18:347-360. https://doi.org/10.1002/(SICI)1098 -1128(199809) 18:5<347::AID-MED5>3.0.CO;2-T.

Kristo, E., Z. Miao, and M. Corredig. 2011. The role of exopolysaccharide produced by Lactococcus lactis ssp. cremoris in structure formation and recovery of acid milk gels. Int. Dairy J. 21:656-662. https://doi.org/10.1016/j.idairyj.2011.02.002.

Lazaridou, A., A. Serafeimidou, C. G. Biliaderis, T. Moschakis, and N. Tzanetakis. 2014. Structure development and acidification kinetics in fermented milk containing oat $\beta$-glucan, a yogurt culture and a probiotic strain. Food Hydrocoll. 39:204-214. https://doi.org/10 .1016/j.foodhyd.2014.01.015.

Lazaridou, A., H. Vaikousi, and C. G. Biliaderis. 2008. Impact of mixed-linkage $(1 \rightarrow 3,1 \rightarrow 4) \beta$-glucans on physical properties of acid-set skim milk gels. Int. Dairy J. 18:312-322. https://doi.org/ 10.1016/j.idairyj.2007.08.005.

Lee, W. J., and J. A. Lucey. 2004. Structure and physical properties of yogurt gels: Effect of inoculation rate and incubation temperature. J. Dairy Sci. 87:3153-3164. https://doi.org/10.3168/jds.S0022 $-0302(04) 73450-5$.

Lee, W. J., and J. A. Lucey. 2006. Impact of gelation conditions and structural breakdown on the physical and sensory properties of stirred yogurts. J. Dairy Sci. 89:2374-2385. https://doi.org/10 .3168/jds.S0022-0302(06)72310-4.

Li, C., L. M. Lin, F. Sui, Z. M. Wang, H. R. Huo, L. Dai, and T. L. Jiang. 2014. Chemistry and pharmacology of Siraitia grosvenorii: A review. Chin. J. Nat. Med. 12:89-102. https://doi.org/10.1016/ S1875-5364(14)60015-7.

Li, S., Y. Zhao, L. Zhang, X. Zhang, L. Huang, D. Li, C. Niu, Z. Yang, and Q. Wang. 2012. Antioxidant activity of Lactobacillus plantarum strains isolated from traditional Chinese fermented foods. Food Chem. 135:1914-1919. https://doi.org/10.1016/j.foodchem .2012.06.048.

Lu, A. M., and Z. Y. Zhang. 1984. The genus Siraitia merr. in China. Guihara 4:27-33.

Lucey, J. A., and H. Singh. 1997. Formation and physical properties of acid milk gels: A review. Food Res. Int. 30:529-542. https://doi .org/10.1016/S0963-9969(98)00015-5.

Miele, N. A., E. K. Cabisidan, G. Blaiotta, S. Leone, P. Masi, R. Di Monaco, and S. Cavella. 2017a. Rheological and sensory performance of a protein-based sweetener (MNEI), sucrose, and aspartame in yogurt. J. Dairy Sci. 100:9539-9550. https://doi.org/10 .3168/jds.2017-12894.

Miele, N. A., E. K. Cabisidan, A. Galiñanes Plaza, P. Masi, S. Cavella, and R. Di Monaco. 2017b. Carbohydrate sweetener reduction in beverages through the use of high potency sweeteners: Trends and new perspectives from a sensory point of view. Trends Food Sci Technol. 64:87-93. https://doi.org/10.1016/j.tifs.2017.04.010.

Moure, A., P. Gullón, H. Domínguez, and J. C. Parajó. 2006. Advances in the manufacture, purification and applications of xylo-oligosaccharides as food additives and nutraceuticals. Process Biochem. 41:1913-1923. https://doi.org/10.1016/j.procbio.2006.05.011.

Muniandy, P., A. B. Shori, and A. S. Baba. 2016. Influence of green, white and black tea addition on the antioxidant activity of probiotic yogurt during refrigerated storage. Food Packag. Shelf Life 8:1-8. https://doi.org/10.1016/j.fpsl.2016.02.002.

Murphy, S. P., and R. K. Johnson. 2003. The scientific basis of recent US guidance on sugars intake. Am. J. Clin. Nutr. 78:827S-833S. https://doi.org/10.1093/ajcn/78.4.827S. 
Pachekrepapol, U., D. S. Horne, and J. A. Lucey. 2015. Effect of dextran and dextran sulfate on the structural and rheological properties of model acid milk gels. J. Dairy Sci. 98:2843-2852. https:// doi.org/10.3168/jds.2014-8660.

Pinheiro, M. V. S., M. N. Oliveira, A. L. B. Penna, and A. Y. Tamime. 2005. The effect of different sweeteners in low-calorie yogurts: A review. Int. J. Dairy Technol. 58:193-199. https://doi.org/10 .1111/j.1471-0307.2005.00228.x.

Prasanna, P., A. Grandison, and D. Charalampopoulos. 2013. Microbiological, chemical and rheological properties of low fat set yoghurt produced with exopolysaccharide (EPS) producing Bifidobacterium strains. Food Res. Int. 51:15-22. https://doi.org/10.1016/j .foodres.2012.11.016.

Qi, X. Y., W. J. Chen, L. Q. Zhang, and B. J. Xie. 2008. Mogrosides extract from Siraitia grosvenori scavenges free radicals in vitro and lowers oxidative stress, serum glucose, and lipid levels in alloxaninduced diabetic mice. Nutr. Res. 28:278-284. https://doi.org/10 .1016/j.nutres.2008.02.008.

Ramirez-Santiago, C., L. Ramos-Solis, C. Lobato-Calleros, C. PeñaValdivia, E. J. Vernon-Carter, and J. Alvarez-Ramírez. 2010. Enrichment of stirred yogurt with soluble dietary fiber from Pachyrhizus erosus L. Urban: Effect on syneresis, microstructure and rheological properties. J. Food Eng. 101:229-235. https://doi .org/10.1016/j.jfoodeng.2010.06.023.

Ramírez-Sucre, M. O., and J. F. Vélez-Ruiz. 2013. Physicochemical, rheological and stability characterization of a caramel flavored yogurt. Lebensm. Wiss. Technol. 51:233-241. https://doi.org/10 $.1016 / j . l w t .2012 .09 .014$.

Takasaki, M., T. Konoshima, Y. Murata, M. Sugiura, H. Nishino, H. Tokuda, K. Matsumoto, R. Kasai, and K. Yamasaki. 2003. Anticarcinogenic activity of natural sweeteners, cucurbitane glycosides, from Momordica grosvenori. Cancer Lett. 198:37-42. https://doi .org/10.1016/S0304-3835(03)00285-4.

Walstra, P. 1990. On the stability of casein micelles. J. Dairy Sci. 73:1965-1979. https://doi.org/10.3168/jds.S0022-0302(90)78875 $-3$.

Wang, W., Y. Bao, G. M. Hendricks, and M. Guo. 2012. Consistency, microstructure and probiotic survivability of goats' milk yoghurt using polymerized whey protein as a co-thickening agent. Int. Dairy J. 24:113-119. https://doi.org/10.1016/j.idairyj.2011.09.007.

Wang, X., E. Kristo, and G. LaPointe. 2019. The effect of apple pomace on the texture, rheology and microstructure of set type yogurt. Food Hydrocoll. 91:83-91. https://doi.org/10.1016/j.foodhyd.2019 .01.004.

Wee, M., V. Tan, and C. Forde. 2018. A comparison of psychophysical dose-response behaviour across 16 sweeteners. Nutrients 10:1632. https://doi.org/10.3390/nu10111632.

Xu, F., D.-P. Li, Z.-C. Huang, F.-L. Lu, L. Wang, Y.-L. Huang, R.F. Wang, G.-X. Liu, M.-Y. Shang, and S.-Q. Cai. 2015. Exploring in vitro, in vivo metabolism of mogroside $\mathrm{V}$ and distribution of its metabolites in rats by HPLC-ESI-IT-TOF-MSn. J. Pharm. Biomed. Anal. 115:418-430. https://doi.org/10.1016/j.jpba.2015 .07 .024 .

Yan, F., N. Li, Y. Yue, C. Wang, L. Zhao, S. E. Evivie, B. Li, and G. Huo. 2020. Screening for potential novel probiotics with dipeptidyl peptidase IV-inhibiting activity for type 2 diabetes attenuation in vitro and in vivo. Front. Microbiol. 10:2855. https://doi.org/10 3389/fmicb.2019.02855.

Zhang, T., C. H. Jeong, W. N. Cheng, H. Bae, H. G. Seo, M. C. Petriello, and S. G. Han. 2019. Moringa extract enhances the fermentative, textural, and bioactive properties of yogurt. Lebensm. Wiss. Technol. 101:276-284. https://doi.org/10.1016/j.lwt.2018.11.010.

Zhou, G., Y. Zhang, Y. Li, M. Wang, and X. Li. 2018. The metabolism of a natural product mogroside $\mathrm{V}$, in healthy and type 2 diabetic rats. J. Chromatogr. B Analyt. Technol. Biomed. Life Sci. 1079:25-33. https://doi.org/10.1016/j.jchromb.2018.02.002.

Zhou, Y., Y. Zheng, J. Ebersole, and C. F. Huang. 2009. Insulin secretion stimulating effects of mogroside $\mathrm{V}$ and fruit extract of luo han kuo (Siraitia grosvenori Swingle) fruit extract. Yao Xue Xue Bao [Acta pharmaceutica Sinica] 44:1252-1257.

\section{ORCIDS}

Qingfeng Ban (1) https://orcid.org/0000-0001-7305-8447

Xiaomeng Sun @ \ttps://orcid.org/0000-0002-1132-8584 